\title{
Risk Factors of Atrial Fibrillation Following Coronary Artery Bypass Grafting A Preliminary Report
}

\author{
Maciej Banach, MD; Jacek Rysz, PhD*; Jarosław Drozdz, PhD**; \\ Piotr Okonski, MD, PhD; Malgorzata Misztal, $\mathrm{PhD}^{\dagger}$; Marcin Barylski, MD ${ }^{\dagger \dagger}$; \\ Robert Irzmanski, PhD ${ }^{\dagger \dagger}$; Janusz Zaslonka, PhD
}

\begin{abstract}
Background To evaluate the risks factors of atrial fibrillation (AF) following coronary artery bypass grafting (CABG).

Methods and Results Twelve hundred patients subjected to CABG were included. Postoperative AF developed in 278 patients (23.2\%). Statistical analysis identified 5 independent predictors of AF: advanced age, history of supraventricular arrhythmias, preoperative heart failure, operation with standard CABG technique and repeated revascularization.

Conclusions Postoperative AF caused a significant increase in mortality and hospitalization length. There were 4 independent risk factors of postoperative AF. Administration of $\beta$-blockers and the OPCAB (off-pump CABG) operating technique were identified as protective factors. (Circ J 2006; 70: 438 -441)
\end{abstract}

Key Words: Atrial fibrillation; Risk factors; Surgical revascularization

$\Delta$ trial fibrillation (AF) is one of the most common complications following cardiac surgery, which occurs, according to various authors, with frequency of 10 to $50 \%$, depending on definitions and diagnostic methods! AF usually appears between 2 and 4 days after surgery and often returns during the first 30 days of the postoperative period? Recently AF has been noted more often and is probably connected with the widening of the group of patients undergoing coronary artery bypass grafting $(\mathrm{CABG})$ or other open-heart operations, and thereby as the result of a reduction of contraindications? Suitable treatment and prevention of postoperative $\mathrm{AF}$ is important patients' improved health and faster rehabilitation, and also reducing hospitalization costs. In spite of the existence of unique guidelines from the American Heart Association, European Society of Cardiology and American College of Cardiology, there are still doubts related to the selection of antiarrhythmic drugs, timing of therapy, duration of treatment and prevention of renewed occurrences ${ }^{4-7}$

The aim of the present study was to evaluate the pre-, intra- and postoperative risk factors of $\mathrm{AF}$ after $\mathrm{CABG}$. The separation of significant predictors of postoperative

(Received October 6, 2005; revised manuscript received December 21, 2005; accepted January 23, 2006)

Department of Cardiac Surgery, University Hospital No 3, $* 2^{\text {nd }}$ Department of Family Medicine, University Hospital No 2, **2nd Department of Cardiology, Bieganski Hospital, Medical University of Lodz, Department of Statistical Methods, University of Lodz, and tDepartment of Internal Diseases and Cardiological Rehabilitation, University Hospital No 5, Medical University in Lodz, Lodz, Poland The study was presented during the annual meeting of the Heart Failure Association (HFA) of the European Society of Cardiology (Heart Failure 2005), 11-14 June 2005, Lisbon, Portugal.

Mailing address: Maciej Banach, MD, Department of Cardiac Surgery, Medical University of Lodz, University Hospital No 3, Sterlinga St. 1/3, 91-425 Lodz, Poland. E-mail: maciej.banach@kardiolog.pl
AF might be helpful in the effective prevention of this complication, which may cause a reduction in costs and the duration of the hospitalization of patients following cardiac surgery.

\section{Methods}

Twelve hundred patients with isolated coronary artery disease who underwent surgical revascularization between 2000 and 2003 in the Department of Cardiac Surgery in Lodz, Poland were included to the study. The mean age of the patients was $61 \pm 2.4$ years; there were $799(66.6 \%)$ men and 401 (33.4\%) women. One hundred fifty (12.5\%) patients were operated on without extracorporeal circulation (OPCAB: Off-Pump Coronary Artery Bypass) and $1,050(87.5 \%)$ with standard CABG. All patients subjected to standard CABG were operated at normothermia with the use of cold crystalloid cardioplegia. Indications for OPCAB included patients who were considered high risk for onpump CABG because of medical comorbidities such as renal failure $(\mathrm{RF})$, diffuse cerebrovascular and peripheral vascular disease, aortic atherosclerosis, chronic obstructive pulmonary disease and religious convictions that precluded blood transfusions. Due to the limited experience of staff in the Department, only patients with significant changes in up to 3 coronary arteries (mean number of grafts: $1.47 \pm 0.97$ ) qualified for the OPCAB method. The mean EuroSCORE score for the patients subjected to $\mathrm{CABG}$ and $\mathrm{OPCAB}$ was: $5.33 \pm 2.49$ and $5.55 \pm 2.57$ ( $>0.05$ ), respectively, and the mean Polish Scale of Risk (PSR) score for patients subjected to $\mathrm{CABG}$ and $\mathrm{OPCAB}$ was: $4.19 \pm 2.76$ and $3.45 \pm$ 2.94 ( $>0.05$ ) respectively? The average number of implemented grafts $(\mathrm{CABG}+\mathrm{OPCAB})$ was $2.68 \pm 1.79$ (range: 1-6). The mean Body Surface Area and Body Mass Index were $1.83 \pm 0.17$ and $26.12 \pm 3.42$ respectively. Almost $28 \%$ 
(334 patients) had some history of supraventricular and ventricular arrhythmias. The mean preoperative ejection fraction (EF) was $41 \pm 3.8 \%, 144(12 \%)$ patients had unstable ischemic heart disease and $96(8 \%)$ had experienced cardiac infarction in the last 90 days. Two hundred and forty-three $(20.3 \%)$ patients examined had prior coronary angioplasty (Percutaneous Transluminal Coronary Angioplasty) with/without stent implementation and 47 (3.9\%) underwent repeated surgical revascularization (reCABG) due to restenosis. There were the following concomitant diseases in this group of patients: hypertension (816 patients; 68\%), diabetes mellitus $(\mathrm{n}=288 ; 24 \%)$, pulmonary obturative disease $(n=52 ; 4.3 \%)$, heart failure $(\mathrm{HF})(\mathrm{n}=52$; $4.3 \%)$ and RF $(n=44 ; 3.7 \%)$. Detailed characteristics are shown in Table 1.

The following outcomes were obtained on the basis of preliminary data from PSR of coronary artery complications database. In 1999, after a short pilot study, a structured questionnaire (590 questions) was constructed to assess the pre-, intra- and postoperative status of any patient included in that study. During the years 2000-2003, 1,200 patients undergoing $\mathrm{CABG}$ in the Department of Cardiac Surgery in Lodz, Poland were interviewed and the questionnaires filled in. Data from the hospital medical records were also collected. Statistical analyses were performed with STATISTICA PL Software. The potential association of each of the considered risk factors with the postoperative outcome was first calculated using univariate nonparametric analysis: chi-squared test or Mann-Whitney's test. Factors significant to at least $\mathrm{p}<0.10$ were then analyzed using multivariate logistic regression analysis and discriminant analysis. Multivariate logistic regression analysis (odds ratio (OR), $\pm 95 \%$ confidence interval $(\mathrm{CI}), \mathrm{p}$ value) was used to identify the independent clinical predictors of postoperative AF.
Table 1 Detailed Characteristics of 1,200 Patients Included to the Study

\begin{tabular}{lc}
\hline \hline Age (years) & $799 / 401(66.6 / 33.4 \%)$ \\
Sex $(M / F)$ & $1.83 \pm 0.17$ \\
BSA & $26.12 \pm 3.42$ \\
BMI & $41 \pm 3.8$ \\
EF $(\%)$ & $334(28 \%)$ \\
Arrhythmias $(n)$ & $144(12 \%)$ \\
Unstable CAD $(n)$ & $96(8 \%)$ \\
Cardiac infarct $(\leq 90$ days $)(n)$ & $243(20.3 \%)$ \\
PTCA $(n)$ & $47(3.9 \%)$ \\
reCABG $(n)$ & $2.68 \pm 1.79$ \\
Grafts $(n)$ & $816(68 \%)$ \\
HA $(n)$ & $288(24 \%)$ \\
DM $(n)$ & $52(4.3 \%)$ \\
$P O D(n)$ & $52(4.3 \%)$ \\
HF $(n)$ & $44(3.7 \%)$ \\
$R F(n)$ &
\end{tabular}

$B S A$, body surface area; BMI, body mass index; $E F$, ejection fraction; $C A D$, coronary artery disease; PTCA, percutaneous transluminal coronary angioplasty; $C A B G$, coronary artery bypass grafting; HA, arterial hypertension; $D M$, diabetes mellitus; $P O D$, pulmonary obturative disease; HF, heart failure; $R F$,renal failure.

Since these models were created and tested using the local data (only from Lodz Province) to assess the predictive power of the models obtained, a second study was required. The present study has a multicenter characteristics. Data from 12 Polish Cardiac Departments have been being collected and by the end of 2005 the outcomes from almost 5,000 patients will have been received?

\section{Results}

Postoperative AF developed in 278 patients (23.2\%). The characteristics of patients with $\mathrm{AF}$ and a comparison

Table 2 Detailed Characteristics of Patients With Atrial Fibrillation $[\mathrm{AF}(+)=278]$ and Comparison to Patients Without AF $[\mathrm{AF}(-)=922]$

\begin{tabular}{|c|c|c|c|}
\hline & $\begin{array}{c}A F(+) \\
n(\%)\end{array}$ & $\begin{array}{l}A F(-) \\
n(\%)\end{array}$ & $p$ value \\
\hline$N$ & $278(23.2)$ & $922(76.8)$ & - \\
\hline Age (years) & $66 \pm 7.8$ & $60 \pm 13.4$ & $<0.01$ \\
\hline $\operatorname{Sex}(M / F)$ & $184(66.2) / 94(33.8)$ & $615(66.7) / 307(33.3)$ & $N S$ \\
\hline$B S A$ & $1.84 \pm 0.19$ & $1.82 \pm 0.47$ & $N S$ \\
\hline$B M I$ & $26.52 \pm 3.15$ & $26.04 \pm 2.77$ & $N S$ \\
\hline History of arrhythmias & $141(50.7)$ & 195 (20.9) & $<0.001$ \\
\hline$H A$ & $202(72.7)$ & $614(66.6)$ & $N S$ \\
\hline$D M$ & $74(26.6)$ & $214(23.3)$ & $N S$ \\
\hline$P O D$ & $11(39.6)$ & $41(44.5)$ & $N S$ \\
\hline$H F$ & $17(6.1)$ & $35(3.8)$ & 0.02 \\
\hline Preoperative $R F$ & $14(5.0)$ & $30(3.3)$ & $<0.05$ \\
\hline Postoperative $R F$ & $49(17.6)$ & $58(6.3)$ & $<0.001$ \\
\hline Use of $\beta$-blockers preoperatively & $187(67.3)$ & $710(77.0)$ & 0.01 \\
\hline$C A B G / O P C A B$ & $249(89.6) / 29(10.4)$ & $801(86.7) / 121(13.1)$ & $<0.05 / 0.03$ \\
\hline reCABG & $12(4.3)$ & $35(3.8)$ & $<0.01$ \\
\hline Number of grafts & $2.71 \pm 1.74$ & $2.58 \pm 1.64$ & NS \\
\hline Duration on ICU* stay (days) & $2.8 \pm 1.9$ & $2.2 \pm 1.4$ & $<0.01$ \\
\hline Duration on hospital stay (days) & $12.9 \pm 7.8$ & $9.4 \pm 5.2$ & $<0.001$ \\
\hline \multicolumn{4}{|l|}{ Major complications } \\
\hline Stroke & $15(5.4)$ & $18(1.9)$ & $<0.05$ \\
\hline Respiratory** & $16(5.8)$ & $29(3.2)$ & $<0.05$ \\
\hline Low output syndrome & $38(13.7)$ & $87(9.4)$ & 0.03 \\
\hline Hospital mortality (\%) & $16(5.8)$ & $28(3.0)$ & $<0.02$ \\
\hline
\end{tabular}

*ICU, intensive care unit; **Respiratory complications included: pleural effusion, pneumonia, pneimpnia, atelectasis, and other conditions requiring prolonged intubation $(>24 \mathrm{~h})$ or reintubation.

See Table 1 for definition of abbreviations. OPCAB, off-pump coronary artery bypass. 
Table 3 Pre-, Intra-, and Postoperative Significant Risk Factors of Atrial Fibirillation Following Surgical Revascularization

\begin{tabular}{llcc}
\hline \hline Predictor & pvalue & $\begin{array}{c}\text { Adjusted } \\
\text { odds ratio }\end{array}$ & $\begin{array}{c}95 \% \text { confidence } \\
\text { interval }\end{array}$ \\
\hline Preoperative & & & \\
EF $<35 \% *$ & $<0.005$ & 4.8 & $1.6-21.4$ \\
$\quad$ Age $>70$ years* & $<0.001$ & 2.6 & $1.7-4.3$ \\
$\quad$ Supraventricular arrhythmias in history* & $<0.002$ & 6.1 & $2.4-14.7$ \\
$\quad$ Chronic renal failure (grade II) & $<0.003$ & 1.9 & $1.0-7.5$ \\
Intraoperative & $<0.01$ & 2.9 & $1.6-5.2$ \\
$\quad$ CABG techique* & $<0.01$ & 2.1 & $1.5-3.9$ \\
Repeated surgical revascularization* & & & \\
Postoperative & $<0.05$ & 1.4 & $1.1-1.9$ \\
$\quad$ Pulmonary congestion and respiratory insufficiency & $<0.05$ & 1.7 & $1.1-4.9$ \\
$\quad$ Renal failure & $<0.05$ & 1.7 & $1.3-2.1$ \\
Application of catecholamines & & & \\
\hline
\end{tabular}

*Independent risk factors. $E F$, ejection fraction; $C A B G$, coronary artery bypass grafting.

with patients without AF is presented in Table 2. According to statistical analysis, factors significantly associated with AF were: left ventricular failure $(\mathrm{EF}<35 \%)$ in the preoperative period $(\mathrm{p}<0.005)$, age $\geq 70$ years $(\mathrm{p}<0.001)$, history of supraventricular arrhythmias $(\mathrm{p}<0.002)$, preoperative chronic RF (usually grade II: mild chronic failure) ( $<<0.03)$, operation using the standard $\mathrm{CABG}$ technique $(\mathrm{p}<0.01)$, repeated surgical revascularization $(\mathrm{p}<0.01)$, postoperative pulmonary congestion and respiratory insufficiency $(\mathrm{p}<$ $0.05)$, postoperative $R F(p<0.05)$ and use of catecholamines in the postoperative period $(\mathrm{p}<0.05)$ (Table 3$)$. Pre- and post-operative administration of Vaughan-Williams class II antiarrhythmic agents ( $\beta$-blockers) were considered as protective factors (OR 0.79 ; 95\% CI $0.50-1.25$; $\mathrm{p}<0.01$ ). Patients who underwent surgical revascularization with the OPCAB technique showed significantly lower frequency of postoperative AF (OR=0.75; 95\% CI $0.72-0.87 ; \mathrm{p}=0.02)$. $\mathrm{AF}$ in the postoperative period was associated with an increase in the length of hospital stay $(12.9 \pm 7.8$ days vs 9.4 \pm 5.2 days, $\mathrm{p}<0.001)$, with a greater incidence of stroke (15 and 28 events in $\mathrm{AF}(+)$ and $\mathrm{AF}(-)$ respectively, $\mathrm{p}<0.05)$ and postoperative death $(16$ and 28 deaths in $\mathrm{AF}$ $(+)$ and $\mathrm{AF}(-)$ respectively, $\mathrm{p}<0.02)$ (in comparison with remained 922 patients without postoperative $\mathrm{AF}$ ) (Table 2). Multivariate logistic regression and discriminant analysis identified 5 independent predictors of AF: advanced age (70 years and more), history of supraventricular arrhythmias, preoperative $\mathrm{HF}(\mathrm{EF}<35 \%)$, operation with standard $\mathrm{CABG}$ technique and repeated surgical revascularization for the sake of coronary arteries (or coronary grafts) restenosis occurrence.

\section{Discussion}

$\mathrm{AF}$ is one of the most common complications following cardiosurgical operations, having an influence on a worsening of the postoperative state, the length of the hospitalization and considerably increasing hospital costs. Currently there are many studies being undertaken with the aim of determining the predictors of postoperative $\mathrm{AF}$ ? In almost all available studies concerning the matter discussed herein (eg, Shingu et al), researchers suggest that advanced age is a significant and independent predictor of postoperative $\mathrm{AF}^{10}$ In Mueller and colleagues' study, the authors analyzed 24 risk factors and proved that right coronary artery disease, age and diabetes are independent risk factors for postoperative AF. It was contemporaneously stated that carrying out small, invasive interventions had an influence on reducing this complication!1 ${ }^{1}$ Similar results were obtained in Siebert's study, in which author analyzed the appearance of $\mathrm{AF}$ in patients following standard CABG (891 persons, AF was found in 164 patients [43\%]) vs the OPCAB method (167 persons; AF was found in 28 patients [16\%]). In contrast to results of Mueller, he observed that there were no statistical differences between the groups $(\mathrm{p}=0.451) !^{2}$ His outcomes were confirmed in the study of Enc et al, who unequivocally stated that there is no reduction of $\mathrm{AF}$ rate in myocardial revascularization without cardiopulmonary bypass. He also observed that prophylactic $\beta$-blocker usage decreased the incidence of AF after both on-pump and off-pump myocardial revascularization $!^{13}$ According to the results of many opposing studies related to postoperative $\mathrm{AF}$ following $\mathrm{CABG}$ or OPCAB surgery, a large, multicenter study should be performed in order to clear this problem up finally! 12,13

Our preliminary results partially confirmed the results obtained by other authors; however, some risk factors are completely new and oppose the outcomes above.

In conclusion, the incidence of $\mathrm{AF}$ in the postoperative period was high and caused a significant increase in mortality and the length of hospital stay. Of the risk factors, advanced age, history of supraventricular arrhythmias, HF, operation with standard CABG and repeated revascularization were significant and independent. The administration of $\beta$-blockers and operation with OPCAB technique were identified as protective factors. A large, multicenter study should be performed to confirm these results. On the basis of the outcomes obtained, the prophylactic treatment (preand postoperative) should be administered in the group of patients with the high risk of AF occurrence ${ }^{14}$

\section{References}

1. Creswell LL, Damiano RJ. Postoperative atrial fibrillation: An old problem crying for new solutions. J Thorac Cardiovasc Surg 2001; 12: $638-641$.

2. Banach M, Okonski P, Zaslonka J. Atrial fibrillation following cardiosurgical operations - current guidelines of pharmacotherapy and invasive treatment. Pol J Surg 2005; 77: 398-412.

3. Gilligan DM. Atrial fibrillation. N Engl J Med 2001; 345: 620.

4. Kato T, Yamashita T, Sagara K, Iinuma H, Fu LT. Progressive nature of paroxysmal atrial fibrillation: Observations from a 14-year followup study. Circ J 2004; 68: 568-572.

5. Banach M, Ostrowski S, Jaszewski R, Knopik J, Zaslonka J, Okonski P. Risk factors of atrial fibrillation after coronary artery bypass grafting. Eur J Heart Fail 2005; 4(Suppl 1): 18.

6. Koitabashi T, Inomata T, Niwano S, Nishii M, Takeuchi I, Nakano 
$\mathrm{H}$, et al. Paroxysmal atrial fibrillation coincident with cardiac decompensation is a predictor of poor prognosis in chronic heart failure. Circ J 2005; 69: 823-830.

7. ACC/AHA/ESC guidelines for the management of patients with atrial fibrillation. Eur Heart J 2001; 22: 1852 - 1923.

8. Okonski P, Szymanska E, Jaszewski R, Zaslonka J, Banach M, Misztal M, et al. Lodz surgical risk scale: Practical use of the statisti$\mathrm{cal}$ analysis of the risk related to the surgical treatment of coronary artery disease. Pol J Surg 2004; 76: 899-914.

9. Komatsu T, Nakamura S, Suzuki O, Horiuchi D, Yomogida K, Okumura K. Long-term prognosis of patients with paroxysmal atrial fibrillation depends on their response to antiarrhythmic therapy. Circ J 2004; 68: 729-733.

10. Shingu Y, Aoki H, Oba J, Takigami K, Eya K, Ebuoka N. Atrial fibrillation after isolated coronary bypass surgery. Kyobu Geka 2005; 58: $807-811$.
11. Mueller XM, Tevaearai HT, Ruchat P, Stumpe F, Von Segesser LK. Atrial fibrillation and minimally invasive coronary artery bypass grafting: Risk factor analysis. World J Surg 2002; 26: 639-642.

12. Siebert J, Lewicki L, Mlodnicki M, Rogowski J, Lango R, Anisimowicz L, et al. Atrial fibrillation after conventional and offpump coronary artery bypass grafting: Two opposite trends in timing of atrial fibrillation occurrence? Med Sci Monit 2003; 9: CR137CR141.

13. Enc Y, Ketenci B, Ozsoy D, Camur G, Kayacioglu I, Terzi S, et al. Atrial fibrillation after surgical revascularization: Is there any difference between on-pump and off-pump? Eur J Cardiothorac Surg 2004; 26: 1129-1133.

14. Banach M, Okonski P, Rysz J, Piechowiak M, Barylski M, Irzmanski $\mathrm{R}$, et al. Postoperative mortality and atrial fibrillation before surgical revascularization: Is there a significant link? Clin Exp Med Lett 2005; 48: $19-22$. 